\title{
Inspiratory muscle strength in well-trained male Iranian soccer players: A pilot study
}

\author{
Shahram Mohaghegh \\ Department of Sports and Exercise Medicine, Clinical Research Development Center of Loghman Hakim \\ Hospital, Shahid Beheshti University of Medical Sciences, Tehran, Iran
}

\begin{abstract}
Maximal inspiratory mouth pressure (MIP) is a common measurement of inspiratory muscle strength, which is often used in a variety of exercises for estimation of the inspiratory muscle strength and to evaluate the effects of inspiratory muscle training. An understanding of elite athletes' MIP characteristics is necessary to guide sport-specific inspiratory muscle training programs. The purpose of this pilot study was to investigate and better understand the MIP characteristics of well -trained Iranian male soccer players. In a cross -sectional study, from 14 well trained 19 and 20-year old Iranian male soccer players, weight, height, maximal inspiratory muscle pressure (MIP) and peak inspiratory flow (PIF) were measured. All subjects did not smoke, had at least 3 years competitive experience at club or provincial level, trained at least four times a week during the competitive season, and engage in fitness sessions (e.g. gymnasium training, jogging, cross-training) at least twice a week. Maximal respiratory pressures were measured by having the subject expire completely and then perform a maximum inspiratory maneuver through mouth while the nostrils were closed (Mueller maneuver). Three measurements were done and the best score was recorded. Mean and Standard deviations of weight, height, MIP and PIF were 73.6(6.6) kg, 179.5(6.7) cm, 99.21(32.34) $\mathrm{cmH20}$ and 5.57(1.46) lit/s respectively. There have not been reported any national MIP values for healthy Iranian men to compare the measured ones with them. The MIP measured values were within predicted limits for healthy men based on anthropometric data. MIP values were significantly lower than those found in international studies for elite male athletes. There is necessary to conduct further researches with larger sample sizes in different sports and also in healthy sedentary Iranian people to estimate the inspiratory muscle strength in a variety of Iranian athletes.
\end{abstract}

KEY WORDS: RESPIRATORY MUSCLE; PULMONARY FUNCTION; MAXIMAL INSPIRATORY PRESSURE (MIP); INSPIRATORY MUSCLE TRAINING; EXERCISE/PHYSIOLOGY

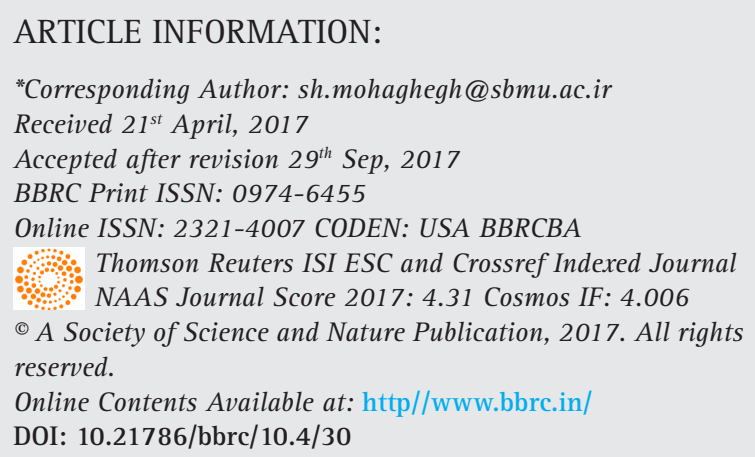




\section{INTRODUCTION}

Maximal inspiratory mouth pressure (MIP) is a common measurement of inspiratory muscle strength, which is often used in a variety of exercises for estimation of the inspiratory muscle strength and to evaluate the effects of inspiratory muscle training, (Klusiewicz 2008). Inspiratory muscle training is classified into two major categories: inspiratory muscle strength training and inspiratory muscle endurance training. Inspiratory muscle strength training is performed by breathing against an external inspiratory load. This load is often adjusted with reference to MIP. Inspiratory muscle training requires participants to achieve a threshold pressure to open the valve of an inspiratory muscle training device (e.g., the POWER breathe inspiratory muscle trainer) to provide an inflow of air. Substantial respiratory strength is needed to achieve and maintain the target threshold pressure, which ranged between 50 and 80\% of MIP in different studies, (HajGhanbari, Yamabayashi et al. 2013).

An understanding of elite athletes' MIP characteristics is necessary to guide sport-specific inspiratory muscle training programs, (Ohya, Hagiwara et al. 2016). The characteristics of MIP have already been reported in both young, (Leech, Ghezzo et al. 1983), and older adults (Summerhill, Angov et al. 2007). To our knowledge, no study has quantified and reported the MIPs of elite Iranian athletes across a variety of sports. An understanding of the characteristics of elite athletes' MIPs is needed to guide inspiratory muscle training programs relative to specific sports. The purpose of this pilot study was to investigate and better understand the MIP characteristics of well -trained Iranian male soccer players.

\section{MATERIAL AND METHODS}

In a cross -sectional study, from 14 well trained 19 and 20-year old Iranian male soccer players, weight, height, maximal inspiratory muscle pressure (MIP) and peak inspiratory flow (PIF) were measured in summer 2014. All subjects did not smoke, had at least 3 years competitive experience at club or provincial level, trained at least four times a week during the competitive season, and engage in fitness sessions (e.g. gymnasium training, jogging, cross-training) at least twice a week. After obtaining written consent, proper device calibration and instruction to participants according to the manual of the device and getting their consent, maximal respiratory pressures were measured by having the subject expire completely and then perform a maximum inspiratory maneuver through mouth while the nostrils were closed (Mueller maneuver). Three measurements were done and the best score was recorded. The measurements were done by an experienced technician using
POWER breathe inspiratory muscle trainer (KH1 pressure threshold device).The predicted MIP was measured based on anthropometric data of athletes using this equation: MIP $=(0.158$ BMI $)-(0.051$ age $)+8.22$, (Hautmann, Hefele et al. 2000). The mean obtained MIP was compared to mean MIP of some male athletes in different sports from different countries using ANOVA test. $\mathrm{P}$ value less than 0.05 was considered significant.

\section{RESULTS AND DISCUSSION}

Mean and Standard deviations of weight, height, MIP and PIF were 73.6(6.6) kg, 179.5(6.7) cm, 99.21(32.34) $\mathrm{cmH} 20$ and 5.57(1.46) lit/s respectively. The MIP measured values were within predicted limits for healthy men based on anthropometric data6. MIP values were significantly lower than those found in most international studies for elite and non-elite male athletes, (Table 1).

Maximal inspiratory pressure (MIP) is a reliable, noninvasive factor for assessing the respiratory muscle function, (Tudorache, Oancea et al. 2010). Recently peak inspiratory flow (PIF) measurement has been of interest as a reliable and accessible tool for assessment of respiratory muscle strength in older adults, (Barnes, Agyapong-Badu et al. 2014).

Maximal inspiratory pressure (MIP) is the most commonly used measure for assessment of inspiratory muscle function. Subjective factors which may influence MIP include proper test performance, weight, age, sex, height, fitness level and smoking status (Sclauser Pessoa, Franco Parreira et al. 2014) and (Harik-Khan, Wise et al. 1998). There is no agreement regarding which of these variables have a significant influence on MIP, (Soori, Mohaghegh et al. 2016).

In this study, Mean and Standard deviations of weight, height, MIP and PIF were 73.6(6.6) kg, 179.5(6.7) $\mathrm{cm}, 99.21(32.34) \mathrm{cmH} 20$ and 5.57(1.46) lit/s respectively. There have not been reported any national MIP values for healthy Iranian men to compare the measured ones with them. MIP values were significantly lower than those found in most international studies for male athletes, (Table 1) (Santos, Rosa et al. 2012) and (Ohya, Hagiwara et al. 2016). This may be the result of differences in measurements of MIP, or anthropometric variations in these studies or sports-specific differences in inspiratory muscle strength or real weaker inspiratory muscles in Iranian athletes; although it is too early for this conclusion as the number of participants in this study was low. The MIP values of some athletes in specific sports such as swimming and rowing tended to be stronger (table 1). It has been mentioned that athletes whose sport typically demands exercise-induced inspiratory muscle fatigue tend to have stronger MIP values than other athletes, (Ohya, Hagiwara et al. 2016). 
Table 1. Mean values of the maximal inspiratory pressure (MIP) in male athletes from various sports (comparison of the published data)

\begin{tabular}{|l|l|l|l|l|l|}
\hline Author & Subjects & Age & Number & MIP $\left(\mathrm{cmH}_{2} \mathbf{0}\right)$ & $\begin{array}{l}\text { Significant difference } \\
\text { with present data } \\
\text { (p value less than 0.05) }\end{array}$ \\
\hline (McConnell, Caine et al. 1997). & $\begin{array}{l}\text { Moderately- trained } \\
\text { individuals }\end{array}$ & $23 \pm 2.8$ & 24 & $158 \pm 29$ & Yes \\
\hline (Fuso, Di Cosmo et al. 1996). & Elite soccer players & $23 \pm 3$ & 27 & $114 \pm 32$ & Yes \\
\hline (Romer, McConnell et al. 2002). & Cyclists and triathletes & $\begin{array}{l}29.5 \pm 3.3 \mathrm{E} \\
30.3 \pm 2.6 \mathrm{C}\end{array}$ & 16 & $\begin{array}{l}102 \pm 6 \mathrm{E} \\
100 \pm 6 \mathrm{C}\end{array}$ & No \\
\hline (Klusiewicz 2008). & Elite rowers & $24.8 \pm 3.2$ & 15 & $157 \pm 23$ & Yes \\
\hline (Klusiewicz 2008). & $\begin{array}{l}\text { Representatives of endurance } \\
\text { sports }\end{array}$ & $17-34$ & 35 & $143 \pm 25$ & Yes \\
\hline (Ohya, Hagiwara et al. 2016). & Elite basketball players & $22.9 \pm 2.0$ & 14 & 126.1 & Yes \\
\hline (Ohya, Hagiwara et al. 2016). & Elite swimmers & $22.1 \pm 2.0$ & 12 & 166.1 & Yes \\
\hline E - Experimental group, C - Control group & & & &
\end{tabular}

Inspiratory muscle fatigue (IMF) occurs after swimming, short-duration high-intensity exercise, and longduration exercise. In swimming, it is required to exactly harmonize the frequency of breathing and tidal volume with stroke mechanics, which causes a different breathing pattern compared with on-land exercise. Also, possible effect of body position on breathing and increased hydrostatic pressure on the chest during swimming result in an increased load on the respiratory system. In running, IMF occurred after a 400-m and 800-mrunning test and additional work from the inspiratory muscles is required, (Ohya, Hagiwara et al. 2016). The relationship between the MIP values and the sport type has to be determined and further researches are warranted.

\section{CONCLUSION}

There is necessary to conduct further researches with larger sample sizes in different sports and also in healthy sedentary Iranian people to estimate the inspiratory muscle strength in a variety of Iranian athletes.

\section{ACKNOWLEDGMENTS}

Thanks to Professor Latif Gachkar for his help in statistical analysis of the data, to Dr Hassan Moghimi and Pneuma Center Corporation for providing the device for measuring MIP and PI.

\section{FINANCIAL DISCLOSURE}

We have no financial interests related to the material in the manuscript.

\section{REFERENCES}

Barnes, N., S. Agyapong-Badu, B. Walsh, M. Stokes and D. Samuel (2014). Reliability and acceptability of measuring sniff nasal inspiratory pressure (SNIP) and peak inspiratory flow (PIF) to assessrespiratory muscle strength in older adults: a preliminary study. Aging Clin Exp Res 26(2): 171-176

Fuso, L., V. Di Cosmo, B. Nardecchia, S. Sammarro, G. Pagliari and R. Pistelli (1996). Maximal inspiratory pressure in elite soccer players. J Sports Med Phys Fitness 36(1): 67-71.

HajGhanbari, B., C. Yamabayashi, T. R. Buna, J. D. Coelho, K. D. Freedman, T. A. Morton, S. A. Palmer, M. A. Toy, C. Walsh, A. W. Sheel and W. D. Reid (2013). Effects of respiratory muscle training on performance in athletes: a systematic review with meta-analyses. J Strength Cond Res 27(6): 1643-16.

Harik-Khan, R. I., R. A. Wise and J. L. Fozard (1998). Determinants of maximal inspiratory pressure. The Baltimore Longitudinal Study of Aging. Am J Respir Crit Care Med 158 (5 Pt 1): $1459-1464$

Hautmann, H., S. Hefele, K. Schotten and R. M. Huber (2000). Maximal inspiratory mouth pressures (PIMAX) in healthy subjects-what is the lower limit of normal? Respir Med 94(7): 689-693.

Klusiewicz, A. (2008). Characteristics of the inspiratory muscle strength in the well-trained male and female athletes. Biology of Sport 25(1): 13-22.

Leech, J. A., H. Ghezzo, D. Stevens and M. R. Becklake (1983). Respiratory pressures and function in young adults. Am Rev Respir Dis 128(1): 17-23.

McConnell, A. K., M. P. Caine and G. R. Sharpe (1997). Inspiratory muscle fatigue following running to volitional fatigue: the influence of baseline strength. Int J Sports Med 18(3): 16

Ohya, T., M. Hagiwara, K. Chino and Y. Suzuki (2016). Maximal inspiratory mouth pressure in Japanese elite male athletes. Respir Physiol Neurobiol 230: 68-72. 
Romer, L. M., A. K. McConnell and D. A. Jones (2002). Effects of inspiratory muscle training on time-trial performance in trained cyclists. J Sports Sci 20(7): 547-562.

Santos, M. L., B. D. Rosa, R. Ferreira Cdos, A. Medeiros Ade and A. P. Batiston (2012). Maximal respiratory pressures in healthy boys who practice swimming or indoor soccer and in healthy sedentary boys. Physiother Theory Pract 28(1): 26-31.

Sclauser Pessoa, I. M., V. Franco Parreira, G. A. Fregonezi, A. W. Sheel, F. Chung and W. D. Reid (2014). Reference values for maximal inspiratory pressure: a systematic review. Can Respir J 21(1): 43-50.
Soori, M., Mohaghegh, S; Hajain,M and Moraadi,B (2016). Effects of Ramadan Fasting on Inspiratory Muscle Function. Asian J Sports Med 7(3): e35201.

Summerhill, E. M., N. Angov, C. Garber and F. D. McCool (2007). Respiratory muscle strength in the physically active elderly. Lung 185(6): 315-320.

Tudorache, V., C. Oancea and O. F. Mlădinescu (2010). Clinical relevance of maximal inspiratory pressure: determination in COPD exacerbation. International Journal of Chronic Obstructive Pulmonary Disease 5: 119-12. 